\title{
Do blushing phobics overestimate the undesirable communicative effects of their blushing?
}

Citation for published version (APA):

de Jong, P. J., \& Peters, M. L. (2005). Do blushing phobics overestimate the undesirable communicative effects of their blushing? Behaviour Research and Therapy, 43, 747-758.

https://doi.org/10.1016/j.brat.2004.06.005

Document status and date:

Published: 01/01/2005

DOI:

10.1016/j.brat.2004.06.005

Document Version:

Publisher's PDF, also known as Version of record

Document license:

Taverne

Please check the document version of this publication:

- A submitted manuscript is the version of the article upon submission and before peer-review. There can be important differences between the submitted version and the official published version of record.

People interested in the research are advised to contact the author for the final version of the publication, or visit the DOI to the publisher's website.

- The final author version and the galley proof are versions of the publication after peer review.

- The final published version features the final layout of the paper including the volume, issue and page numbers.

Link to publication

\footnotetext{
General rights rights.

- You may freely distribute the URL identifying the publication in the public portal. please follow below link for the End User Agreement:

www.umlib.nl/taverne-license

Take down policy

If you believe that this document breaches copyright please contact us at:

repository@maastrichtuniversity.nl

providing details and we will investigate your claim.
}

Copyright and moral rights for the publications made accessible in the public portal are retained by the authors and/or other copyright owners and it is a condition of accessing publications that users recognise and abide by the legal requirements associated with these

- Users may download and print one copy of any publication from the public portal for the purpose of private study or research.

- You may not further distribute the material or use it for any profit-making activity or commercial gain

If the publication is distributed under the terms of Article $25 \mathrm{fa}$ of the Dutch Copyright Act, indicated by the "Taverne" license above, 


\title{
Do blushing phobics overestimate the undesirable communicative effects of their blushing?
}

\author{
Peter J. de Jong ${ }^{\mathrm{a}, *}$, Madelon L. Peters ${ }^{\mathrm{b}}$ \\ ${ }^{a}$ Department of Developmental and Clinical Psychology, University of Groningen, Grote Kruisstraat 1/2, \\ 9712 TS Groningen, The Netherlands \\ ${ }^{\mathrm{b}}$ Department of Medical, Clinical and Experimental Psychology, Maastricht University, The Netherlands
}

Received 28 January 2004; received in revised form 14 May 2004; accepted 1 June 2004

\begin{abstract}
Previous research indicated that blushing has socially threatening revealing effects in ambiguous situations. To explain blushing phobics' fearful preoccupation with blushing, we tested the hypothesis that blushing fearful individuals overestimate its revealing effects. High $(n=20)$ and low $(n=20)$ blushing fearful individuals read vignettes describing prototypical mishaps and ambiguous social events. Participants were prompted in the perspective of the actor, and were asked to indicate their expectations of the observers' judgments (meta-perceptions). Blushing fearful individuals overestimated the probability and the costs of undesirable outcomes. However, this judgmental bias was not inflated by displaying a blush. Thus, the results provide no evidence to support the idea that fear of blushing is fuelled by a biased conception of its communicative effects.
\end{abstract}

(C) 2004 Elsevier Ltd. All rights reserved.

Keywords: Blushing; Social phobia; Judgmental bias; Meta-perception

\section{Introduction}

Blushing is a common emotional response and virtually all people blush at least occasionally (Edelmann, 1990). It predominantly occurs in face-to-face contacts involving shame or

\footnotetext{
${ }^{*}$ Corresponding author.

E-mail address: p.j.de.jong@ppsw.rug.nl (P.J. de Jong).
} 
embarrassment and is usually confined to the facial region (Shields, Mallory, \& Simon, 1990). Despite its common nature, most people consider blushing as an undesirable response, which they often try to stop or to conceal. Some individuals experience even so much distress because of their blushing that they develop a blushing phobia and apply for treatment (e.g., Scholing \& Emmelkamp, 1993). The major aim of the present study is to explain blushing phobics' fearful preoccupation with their blushing.

Previous research has already shown that blushing phobic individuals are not characterized by a relatively low threshold for blushing, or a relatively intense coloration in response to a certain social stressor (Gerlach, Wilhelm, Gruber, \& Roth, 2001; Mulkens, De Jong, Dobbelaar, \& Bögels, 1999; Drummond, 1997). Thus, fear of blushing cannot be simply attributed to a biological predisposition to blush relatively fast or relatively intense. Rather it appears to be fuelled by mechanisms that are irrespective of facial coloration per se. One of the mechanisms that might be involved is a biased interpretation of the communicative value of a blush. Therefore, we took the alleged communicative properties of social blushing (e.g., Leary, Britt, Cutlip II, \& Templeton, 1992; de Jong, 1999) as the starting point to further explore why some people are characterized by a fearful preoccupation of blushing.

Several authors have argued that displaying shame and embarrassment has instrumental value (e.g., Goffman, 1967; Keltner, Young, \& Buswell, 1997). Showing embarrassment or shame would signify the individual's recognition that she/he has committed a social infraction and sincerely regrets it. In its turn this behavior may attenuate the offender's negative social impression and diffuse interpersonal threats (de Waal, 1995). Because of its saliency (qua color and localization) blushing is an obvious candidate of being one of the components of shame and embarrassment that de facto appease the observers (cf. Keltner, 1995; Castelfranchi \& Poggi, 1990).

Indeed, there is evidence that blushing serves a remedial function. In a series of studies (de Jong, 1999; exp.1 \& 2; de Jong, Peters, \& De Cremer, 2003) we found that blushing after a seemingly involuntary mishap (e.g., spilling wine on the observer's clothings) or a voluntary transgression (e.g., damaging someone else's bicycle) attenuated the negative impression of the actor and favorably influenced the attributed seriousness of the incident. In further support of its implied instrumental value, it has been shown that individuals who believed that the researcher did not perceive their blushes in the context of a self-presentational predicament, subsequently engaged in alternative remedial behaviors, whereas participants who thought their blushes were noticed by the experimenter, did not (Leary, Landel, \& Patton, 1996; experiment 2). That is, these individuals acted in a way as if they realized that their blushing served as a remedial gesture.

The remedial effect of blushing seems to reflect a robust phenomenon. However, recent research showed that the favorable effects of the blush on the observers' judgments are restricted to contexts in which actors display clear-cut deviant behavior(s). In more ambiguous social situations, or in situations that are ambiguous with respect to the actors' intentionality, the blush was found to have adverse effects (e.g., de Jong et al., 2003). More specifically, we found that in the absence of a clear-cut predicament, observers interpreted blushing as signaling that the (ambiguous) situation should be considered as an intentional violation of a social standard rather than an innocent, incidental coincidence (de Jong, Peters, De Cremer, \& Vranken, 2002; de Jong et al., 2003). In other words, in the context of behaviors that can be possibly interpreted as a transgression of some kind, displaying a blush may substantiate observers' suspicion that the blusher indeed behaved in a socially inappropriate manner (cf. Leary et al., 1996) ("true innocence 
does not need a blush"). Since most situations involve some ambiguity with respect to the elicitors of a blush, its revealing effects may well prevail its appeasing effects in real life.

This characteristic of the blush may help to explain why people generally consider blushing as an undesirable response which they often try to stop or to conceal (Shields, Mallory, \& Simon, 1990), and why a subgroup of social phobics report (fear of) blushing as being their predominant complaint (e.g., Scholing \& Emmelkamp, 1993; Mulkens et al., 2001). That is, the apparent context-dependent functional properties of the blush may not only influence the actual judgments of the observers (e.g. de Jong et al., 2002), but may also affect the actors' beliefs about the observers' judgments (i.e., the blusher's meta-perception). There is considerable evidence that social phobic individuals are characterized by selective processing of threat-relevant information (Heinrichs \& Hofmann, 2001). Most important for the present context, several studies showed that social phobic individuals overestimate the probability and/or the costs of social events that are generally considered to be socially threatening (e.g., Foa, Franklin, Perry, \& Herbert, 1996). Following this, it could be hypothesized that blushing phobics' fearful preoccupation with blushing is (at least partly) due to a bias to overestimate the undesirable revealing properties of their blushing. More specifically, one would expect phobic individuals overestimating the possibility that others would think that they have done or thought something undesirable (when displaying a blush in an ambiguous situation). Second, such a bias would result in an overestimation of the negative influence of blushing on others' judgment of the actor's dispositional characteristics (cf. de Jong et al., 2002).

The present study was designed to investigate whether, indeed, blushing fearful individuals overestimate the undesirable communicative effects of their blushing. Therefore, we presented blushing fearful and explicitly nonfearful participants with a series of vignettes some of which referred to apparently involuntary mishaps, and some to ambiguous situations that could be interpreted as a transgression, but not necessarily so (cf. de Jong et al., 2003). However, in contrast to previous research prompting participants in the observers' perspective, the present study prompted participants in the perspective of the (blushing) actor. Accordingly, rather than judging others, they judged others' views of themselves. That is, participants were asked to take an outside perspective on one's own behavior and to indicate their beliefs about the impressions they conveyed (by their behavior) to hypothetical others. The prediction most pertinent to our research question is that typically in the context of ambiguous social situations high fearful individuals expect others to attribute more intentionality and more negative traits to blushing actors (i.e., themselves) than low fear individuals.

\section{Method}

\subsection{Participants}

Participants were 40 female undergraduates from Maastricht University. Mean age was 19.6 years (range 18-7 years). They were selected from a larger sample $(N=273)$ on the basis of their scores on the fear of blushing subscale of the Blushing, Trembling, and Sweating Questionnaire (BTS-Q; Bögels \& Reith, 1999). We selected a low fear group $(n=20 ; M=9.2 ; S D=4.2)$ and a high fear group $(n=20 ; M=59.4 ; S D=14.5)$. Mean BTS-Q scores of the high fearful group 
Table 1

Description of the sample

\begin{tabular}{llrll}
\hline & High fear $(n=20)$ & Low fear $(n=20)$ & $t$ & $p$ \\
\hline BTS-Q (0-100) & $59.4(14.5)$ & $9.2(4.2)$ & 15.2 & $<.01$ \\
BPS (0-76) & $46.1(12.8)$ & $23.1(9.1)$ & 6.6 & $<.01$ \\
Brief FNE (0-48) & $28.8(10.1)$ & $14.9(5.8)$ & 5.4 & $<.01$ \\
FQavoidance (0-40) & $18.9(8.5)$ & $7.5(3.7)$ & 5.5 & $<.01$ \\
\hline
\end{tabular}

Note: $\mathrm{BTS}-\mathrm{Q}=$ Blushing, Trembling, and Sweating Questionniare (Blushing subscale); BPS= Blushing Propensity Scale; $F N E=$ fear of negative evaluation; FQ = Fear Questionnaire (Social Phobia subscale).

were comparable to the mean scores that Mulkens et al.(2001) reported for their treatment seeking groups (i.e., 62.3). Participants received a small remuneration in return for their participation (e.g., a chocolate bar).

\subsection{Assessment}

For a more comprehensive description of the sample, participants completed (in addition to the BTS-Q) the extended version of the Blushing Propensity Scale (BPS; Bögels, Alberts, \& de Jong, 1996) that was originally designed by Leary and Meadows (1991), the 12-item version of the Fear of Negative Evaluation Scale (Leary, 1983), and the social phobia subscale of the Fear Questionnaire (FQ; Marks and Mathews, 1979) (see Table 1).

\subsection{Materials and measures}

We used a paper and pencil task, which consisted of a series of vignettes. The social events that were described in the present vignettes, were the same as were successfully employed in previous work (de Jong et al., 2003). Yet, whereas participants in previous experiments had to evaluate the situation being prompted in the perspective of the observer (e.g., "To what extent do you think that the present situation reflects an intentional transgression"), for the present purposes participants were now prompted in the perspective of the actor and were asked to indicate how they would think the observing other would evaluate the situation (e.g., "To what extent do you think that the observer will interpret the present situation as an intentional transgression)".

There were two categories of vignettes. ${ }^{1}$ One category consisted of vignettes describing a typical mishap (e.g., spilling coffee on someone's trousers while pouring out coffee from a thermos jug in a crowded train), and one consisted of vignettes describing an actor who behaves in good faith within the context of an ambiguous situation that could be erroneously interpreted by others as a (intentional) transgression (e.g., the actor posits his/her bag near the dozens of other bags that were already left by some other students; when leaving the library, the actor accidentally takes someone else's bag and is then accosted by the actual owner of the bag). In half of the vignettes, the actors displayed a blush response following the incident. Thus there were 2 Category (mishap vs. ambiguous situation) $\times 2$ actor's response (blush vs. no blush) is 4 different types of vignettes.

\footnotetext{
${ }^{1}$ The exact text of all vignettes that were used in the present study can be obtained from the first author.
} 
To cancel out the influence of particular contexts, we used 4 different (but similar) incidents for each of the two distinct categories of vignettes. These different incidents were systematically varied across the different types of vignettes within each category. Participants were presented with a series of 4 vignettes (one of each type); for each series a particular context appeared only once. To minimize the influence of carry-over effects, the order of vignettes was randomized for each participant. The vignettes were printed on separate sheets. On the cover page participants were instructed that this experiment concerned an investigation into the appraisal of events and they were asked to identify themselves with the description as much as possible.

Each vignette was followed by 5 VASs. To index the revealing properties that participants (implicitly) attribute to their blushing, VAS 1 asked participants to indicate the probability that (hypothetical) others would think that the mishap was the result of an intentional act [mishaps] $(0 \%=0,100 \%=100)$, or the probability that the others would think that the situation should be interpreted as an intentional transgression (rather than a coincidence) [ambiguous situation]. Note that the subjective costs of being revealed as a "transgressor" may vary independently from the anticipated revealing or remedial effects of displaying a blush. Hence, even in the absence of any difference between high and low fear individuals with respect to the anticipated revealing effects of their blushing, high fearful may report inflated levels of subjective costs when being revealed as a "transgressor" (which in turn may give rise to a relatively negative appreciation of the -potentially revealing - blush). Therefore, VAS 2 asked to indicate how distressing it would be for them when others, indeed, would think that the mishap/transgression reflected an intentional act (i.e., subjective costs of being revealed as a "transgressor") (not distressing at all $=0$, very distressing =100). The remaining three VASs were included to test whether typically in ambiguous situations high fearful overestimate the negative consequences of their blushing on others' judgments (cf. de Jong et al., 2003). More specifically, participants were asked to indicate their expectancies with respect to others' evaluation of the situation (VAS 3; not serious at all $=0$, very serious $=100)$, as well as their expectancies with respect to others' evaluation of both their reliability (VAS 4; not at all reliable $=0$, very reliable $=100$ ), and their likeability (VAS 5; very unlikeable $=0$, very likeable $=100$ ). It was stressed that there were no right or wrong answers and that only their personal judgment counts. Participants were tested individually.

\section{Results}

\subsection{Attributed intentionality}

To test whether especially the high fear group would anticipate that others would interpret their blushing in an ambiguous situation as signaling that this situation should be considered as an intentional transgression rather than an innocent coincidence, the 'probability of intentionality' ratings were subjected to a 2 Category (mishap vs. Ambiguous) $\times 2$ Actor's Response (blush vs. no blush) $\times 2$ group (high vs. low fear of blushing) analysis of variance (ANOVA), with the last factor being a between subjects factor. The ANOVA revealed a main effect of Category $[F(1,38)=163.9, p<.0001]$, indicating that in line with the (intended) experimental manipulation, participants' ratings were lowest with respect to the vignettes describing mishaps $(M=18.5$, $S D=18.2$ ) and highest for the vignettes describing ambiguous situations that could be interpreted 
Table 2

Actor's appreciation of the subjective costs and actor's judgments of others' view with respect to attributed intentionality and seriousness of the incident and their dispositions in the context of mishaps and ambiguous events as a function of fear level (high vs. low) and displayed response (blush vs. no blush)

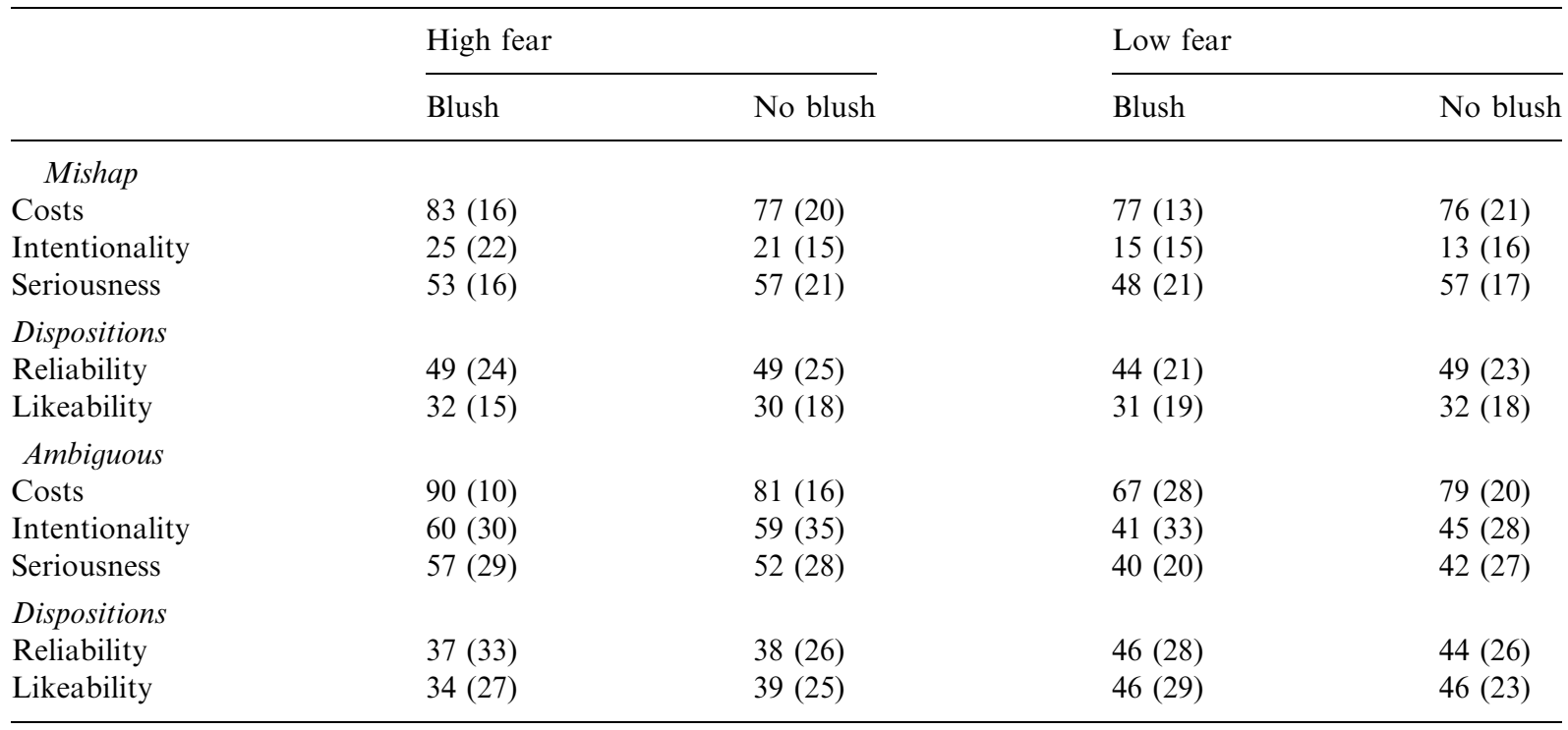

as an intentional transgression but not necessarily so $(M=51.9, S D=30.0)$. This effect was independent of the Actor's Response (blush vs. no blush) $[F(1,38<1)]$, and Group (high fear vs. low fear) $[F(1,38)<1]$. Yet, there was a main effect of Group $[F(1,38)=12.5, p<.001]$, indicating that high fear individuals generally reported higher ratings than low fear individuals with respect to the possibility that others would think that the incidents reflect intentional acts (see Table 2). None of the other effects approached significance.

\subsection{Subjective costs when being judged as a "transgressor"}

To test whether blushing fearful participants report inflated levels of distress (i.e., subjective costs) when others would think that the mishap/transgression reflected an intentional act, the distress ratings were subjected to a 2 Category (mishap vs. ambiguous situation) $\times 2$ Actor's Response (blush vs. no blush) $\times 2$ Group (high vs. low fear) ANOVA. The analysis revealed a main effect of Group $[F(1,38)=5.2, p<.05]$. This main effect was qualified by a significant Group by Category interaction $[F(1,38)=4.1, p<.05]$. Subsequent analyses indicated that there was a significant main effect of Group with respect to the ambiguous situations $[F(1,38)=9.2$, $p<.01]$, but not with respect to the mishaps $[F(1,38)<1]$ (see Fig. 1). This effect reflects the finding that typically in ambiguous contexts high fear individuals consider it more distressing than low fear individuals when others would think that the transgression reflects an intentional act (i.e., higher subjective costs of being revealed as a transgressor). In addition, subsequent analyses indicated that for the high fear group the costs tended to be higher in the ambiguous context than in the mishap context $[F(1,19)=3.6, p=.07]$, whereas such a difference was absent in the low 


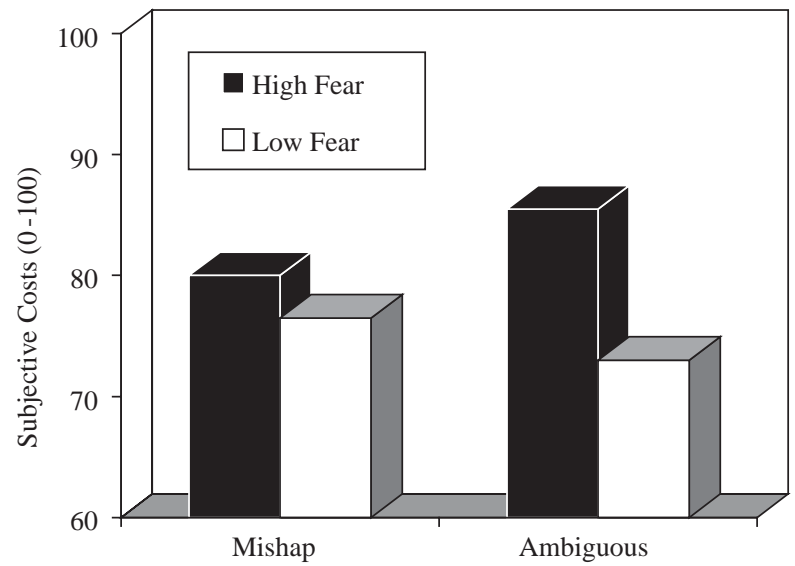

Fig. 1. Subjective costs when being revealed as a "transgressor" as a function of fear (Low vs. high) for both types of incidents (mishap, ambiguous).

fearful group $[F(1,19)<1]$. Thus, it appears that the Group by Context interaction is mainly carried by the relatively high subjective costs that are reported in the ambiguous context by the high fear group (see also Fig. 1).

\subsection{Seriousness of incident}

To test whether the high fear group expected a relatively negative appreciation of the incident by others when displaying a blush in an ambiguous situation, the seriousness ratings were subjected to a 2 Category (mishap vs. ambiguous situation) $\times 2$ Actor's Response (blush vs. no blush) $\times 2$ Group (high vs. low anxious) ANOVA. The analysis revealed a main effect of Group $[F(1,38)=6.3, p<.05]$. This main effect was qualified by a Group $\times$ Category interaction $[F(1,38)=7.0, p<.01]$. Subsequent analyses indicated that the seriousness ratings of both groups differed in the context of the ambiguous situation $[F(1,38)=14.7, p<.001]$ but not with respect to the mishaps $[F(1,38)<1]$. Thus, typically in the ambiguous situation high fear individuals expected others to evaluate the situation as being more serious than the low fear individuals (see Fig. 2). In addition, subsequent analyses revealed that in the low fear group seriousness ratings were significantly lower for the ambiguous context than for the mishap condition $[F(1,19)=4.5$, $p<.05]$, whereas for the high fear group ratings for both contexts were similarily high $[F(1,19)=2.6, p>.1]$. Together these findings indicate that the Group by Context interaction is mainly carried by the relatively high ratings in the high fear group with respect to the ambiguous context (see also Fig. 2). None of the other effects reached the conventional level of significance.

\subsection{Dispositional characteristics}

Reliability: To test whether high fearful individuals anticipated a relatively harsh evaluation by others when displaying a blush in an ambiguous situation, the reliability ratings were subjected to a 2 Category (mishap vs. ambiguous situation) $\times 2$ Actor's Response (blush vs. no blush) $\times 2$ Group (high vs. low fear) ANOVA. The analysis revealed a main effect of category $[F(1,38)=9.5$ 


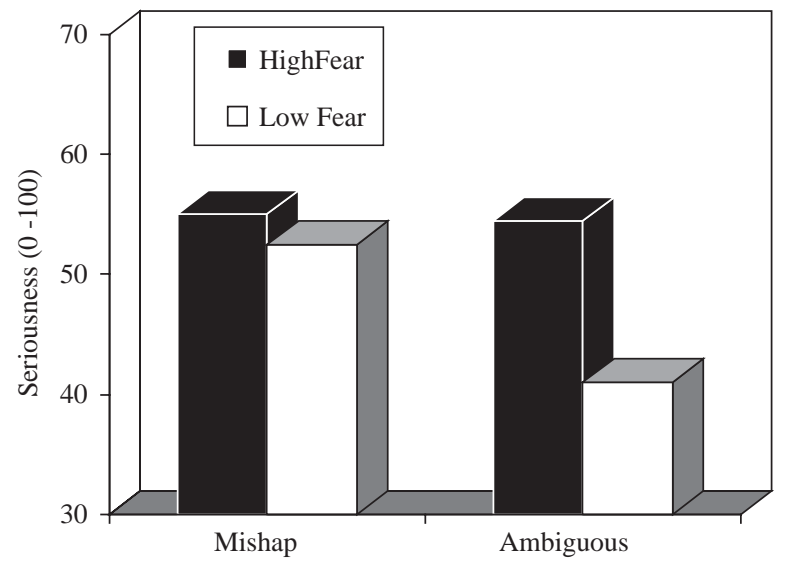

Fig. 2. Anticipated judgment of other people with respect to the seriousness of the incident as a function of the actor's fear level (Low vs. high) and type of incident (Mishap vs. ambiguous).

$p<.001]$, indicating that participants generally expected others to consider the actor (i.e., participants) as less reliable in the context of the ambiguous situation than after a mishap. This effect appeared independent of the actor's response $[F(1,38)<1]$. There was no main effect of Group $[F(1,38)<1]$. Yet, there was a significant Group by Category interaction $[F(1,38)=5.3$, $p<.05]$. Subsequent analyses indicated that there was no main effect of Group in the context of the mishaps. However, in the context of the ambiguous situations there was a tendency to indicate that high fear individuals expected others to judge the actor (i.e., participants) as less reliable than the low fear individuals $[F(1,39)=3.0, p=.08]$. In addition, subsequent analyses indicated that for the high fear group the reliability ratings were significantly lower in the ambiguous context than in the mishap context $[F(1,19)=20.6 p<.01]$, whereas no such difference was evident for the low fear group $[F(1,19)<1]$ (see Fig. 3).

Likeability: To further test whether the high fear group anticipated a relatively negative influence of displaying a blush in ambiguous situations, the likeability ratings were subjected to a 2 Category (mishap vs. ambiguous situation) $\times 2$ Actor's Response (blush vs. no blush) $\times 2$ Group (high vs. low fear) ANOVA. The analysis revealed a main effect of Category $[F(1,38)=8.9$ $p<.01$ ], indicating that participants generally expected others to evaluate the actor (i.e., participant) in the context of the ambiguous situation as less likeable than after a mishap. Although the pattern was very similar to those of the reliability ratings, the Group by Category interaction did not reach significance $[F(1,38)=1.8]$. None of the other effects approached significance.

\section{Discussion}

The major results can be summarized as follows: (i) blushing fearful individuals overestimated the likelihood that others would interpret the mishaps/ambiguous events as reflecting intentional acts; (ii) high fear individuals considered it as particularly distressing when others would (erroneously) interpret their behavior in ambiguous situations as reflecting an intentional 


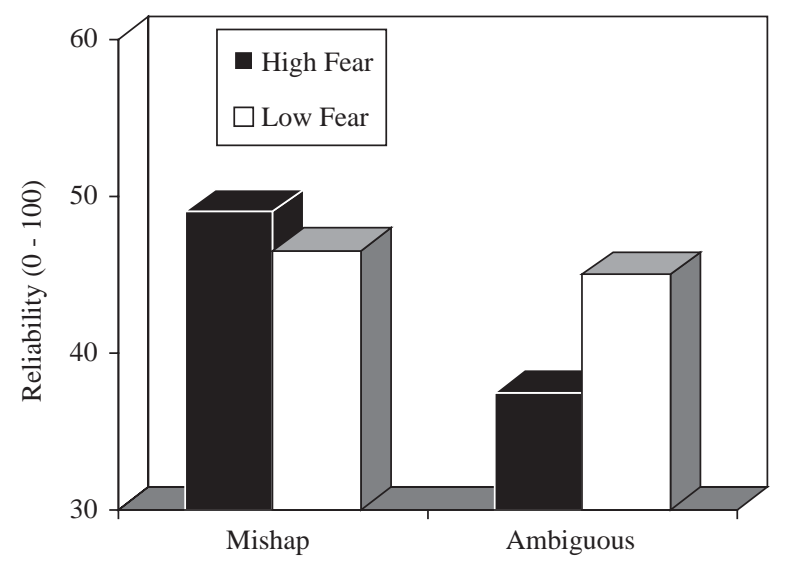

Fig. 3. Anticipated judgment of other people with respect to the actor's (i.e., participant's) reliability as a function of the actor's fear level (Low vs. high) and type of incident (Mishap vs. ambiguous).

transgression; (iii) specifically with respect to the ambiguous situations, high fear individuals expected others to evaluate the situation as being more serious, and the actors as being less reliable than low fear individuals, (iv) neither high nor low fearful individuals anticipated that blushing might positively affect others' judgment in the context of a mishap, nor adversely influence others' judgment in the context of ambiguous social situations.

The present results clearly showed that blushing fearful individuals are characterized by a judgmental bias: High fearful individuals reported relatively high expectancy ratings with respect to the possibility that individuals would interpret their behavior in a socially undesirable way (e.g., as a serious, intentional transgression/mishap rather than as a coincidence), anticipated relatively high levels of subjective costs (i.e., distress) when indeed others would interpret their behavior as a social transgression, and anticipated a relatively harsh evaluation of their dispositional characteristics (i.e., reliability). These findings replicate and extent previous results indicating that individuals suffering from generalized social phobia overestimate the probability and/or the subjective costs of socially threatening events (e.g., making a fool of oneself) (Stopa \& Clark, 2000). In addition, the present finding that this judgmental bias in blushing fearful individuals was especially pronounced in the context of ambiguous situations, is in line with previous work indicating that social phobic individuals tend to choose a negative rather than a positive or neutral interpretation for ambiguous social scenarios (Amir, Foa, \& Coles, 1998), and also implicitly selectively associate ambiguous social events with negative rather than with positive outcomes (e.g., de Jong, Pasman, Kindt, \& van den Hout, 2001).

The presence of such a general bias to anticipate negative other's judgments of the self may logically act in a way to maintain or even enhance blushing phobics' social concerns. Meanwhile, it leaves unexplained why blushing phobic individuals report blushing as being their predominant complaint. To explain this fearful preoccupation with blushing, the present experiment was designed to test the hypothesis that blushing fearful individuals overestimate the negative consequences of displaying a blush in ambiguous social situations (i.e., in the absence of a straightforward elicitor of the blush). However, although blushing fearful individuals generally overestimated the probability of undesirable social outcomes, no evidence emerged to suggest that 
this bias was further intensified by displaying a blush. In fact, contrasting with previous findings indicating that others' judgments of the actor are strongly influenced by the absence/presence of a blush (e.g., de Jong, 1999), neither high nor low fearful individuals expected that their blushing (in ambiguous social situations) would (adversely) influence others' judgment of their behavior or their dispositional characteristics.

One explanation for the apparent absence of an effect of the actor's blush on the anticipated judgment of the observer in the present study might be that the current manipulation was too weak. However, this possibility is not very convincing since exactly the same "blush" manipulation did systematically affect participants' judgments in previous experiments (de Jong, 1999; exp1 \& exp 2; de Jong et al., $2003 \exp 1 \& \exp 2$ ). Another explanation could be that the high fear individuals might have expected/implied to blush in all of the situations described in the vignettes, irrespective of whether this was made explicit or not. Yet, although it is conceivable that such expectancies might have played a role in the high fear group, it is difficult to see why also nofear individuals (who not typically think to blush easily, as is also evidenced by their low BPS scores) would have implied to blush even when this was not made explicit in the scenario. Hence, this would not be a particularly parsimonious explanation for the present pattern of findings that neither the high nor the low fear group anticipated any effect of their blushing on the observer's judgments with respect to their intentions and dispositions. Finally, it should be acknowledged that there was no manipulation check on the identification by the participants with the various situations that were described in the vignettes. Therefore, it cannot be ruled out that various degrees of identification with the situations may have affected the results. Meanwhile, it seems not very likely that a lack of sufficient identification played a major role in the present pattern of findings, since a very similar experimental approach in our previous work did reveal differential results as a function of the actor's response (i.e., absence/ presence of a blush; de Jong et al., 2003).

At this stage, it is important to note that the present study differed in one important respect from previous studies showing remedial and/or revealing effects of blushing (and other displays of embarrassment or shame) (e.g., de Jong et al., 2003; Keltner et al., 1997, Semin \& Manstead, 1982). That is, in all of these earlier studies, the participants themselves had to evaluate the actors, whereas in the present study, participants had to predict how they themselves would be evaluated by others. Germane to this, recent research points to important discrepancies between the processes involved in judging others and in judging others' views of the self (e.g., Vorauer, 2001). When judging others, people tend to readily infer that current behavior reflects the true person/ goal/intention (e.g., "correspondence bias"; Jones \& Davis, 1965); hence, the impression people convey on observers strongly depends on their current behaviors (e.g., their blushing). Yet, when considering the judgments that others form of themselves (i.e., meta-perceptions) people typically underestimate the impact of their current behaviors and exaggerate the extent to which their true self will be evident for the observer ("transparancy overestimation"). Accordingly, people's metaperceptions tend to be most strongly connected to their beliefs about themselves rather than to their current behavior (e.g., Vorauer \& Miller, 1997; exp. 2). Perhaps, then, the most parsimonious explanation for the present absence of an effect of blushing on the anticipated judgments might be that similar processes (e.g., transparancy bias) led the present participants to ignore their blushing when considering the judgment that others would form of them. If so, this would obviously cast serious doubts on the idea that individuals' anticipated revealing effects of the blush might play an important role in blushing phobia. 
To conclude, the present results provide no support for the idea that blushing phobic individuals' fear of blushing is fuelled by a biased conception of the communicative effects of blushing. Perhaps, then, blushing phobic individuals' consider blushing per se as a highly distressing response. This might follow from their coping assumption that one should not convey any sign of uncertainty to others (Mulkens et al., 2001). Therefore, they are likely to consider blushing per se as a self-presentational predicament (Mulkens et al., 1999). Unfortunately, feeling embarrassed because of displaying a blush may well have the ironic effect of further intensifying the blush (de Jong, 1998), which, in turn, promotes the generation of the undesirable negative public image, etc. (Drummond et al., 2003). To explore the validity of these deductions, we currently test whether typically blushing phobic individuals respond with increasing facial blood flow when given false-positive feedback of blushing (cf. Drummond, 2001) in the context of ambiguous social events.

\section{Acknowledgements}

We are grateful to Annie Raven for her assistance during the data acquisition and to Diederik Stapel for his helpful comments on an earlier version of this manuscript.

\section{References}

Amir, N., Foa, E. B., \& Coles, M. E. (1998). Negative interpretation bias in social phobia. Behaviour Research and Therapy, 36, 945-957.

Bögels, S. M., Alberts, M., \& de Jong, P. J. (1996). Self-consciousness, self-focused attention, blushing propensity, and fear of blushing. Personality and Individual Differences, 21, 573-581.

Bögels, S. M., \& Reith, W. (1999). Validity of two questionnaires to assess social fears: The Dutch Social Phobia and Anxiety Inventory and the Fear of Blushing, Trembling, and Sweating Questionnaire. Psychopathology and Behavioral Assessment, 21, 51-66.

Castelfranchi, C., \& Poggi, I. (1990). Blushing as a discourse: Was Darwin wrong? In W. R. Crozier (Ed.). Shyness and embarrassment: Perspectives from social psychology (pp. 230-251). Cambridge: Cambridge University Press.

de Jong, P. J. (1998). Social blushing: A functional perspective. Nederlands Tijdschrift voor de Psychologie, 53, 117-125.

de Jong, P. J. (1999). Communicative and remedial effects of social blushing. Journal of Nonverbal Behavior, 23, $197-218$.

de Jong, P. J., Pasman, W., Kindt, M., \& van den Hout, M. A. (2001). A reaction time paradigm to assess complaintspecific (implicit) dysfunctional associations. Behaviour Research and Therapy, 39, 101-113.

de Jong, P. J., Peters, M., \& de Cremer, D. (2003). Blushing may signify guilt: Revealing effects of blushing in ambiguous social situations. Motivation and Emotion, 27, 225-249.

de Jong, P. J., Peters, M., De Cremer, D., \& Vranken, C. (2002). Blushing after a moral transgression in a prisoner's dilemma game. Appeasing or revealing?. European Journal of Social Psychology, 32, 627-644.

de Waal, F. B. M. (1995). Good natured: The origins of right and wrong in humans and other animals. Cambridge: Harvard University Press.

Drummond, P. (1997). The effects of adrenergic blockade on blushing and facial flushing. Psychophysiology, 34, $163-168$.

Drummond, P. (2001). The effect of true and false feedback on blushing in women. Personality and Individual Differences, 30, 1329-1343. 
Drummond, P., Camacho, L., Formentin, N., Heffernan, T. D., Williams, F., \& Zekas, T. E. (2003). The impact of verbal feedback about blushing on social discomfort and facial blood flow during embarrassing tasks. Behaviour Research and Therapy, 41, 413-425.

Edelmann, R. J. (1990). Chronic blushing, self-consciousness, and social anxiety. Journal of Psychopathology and Behavioral Assessment, 12, 119-127.

Foa, E. B., Franklin, M. E., Perry, K. J., \& Herbert, J. D. (1996). Cognitive biases in generalized social phobia. Journal of Abnormal Psychology, 105, 433-439.

Gerlach, A. L., Wilhelm, F. H., Gruber, K., \& Roth, W. T. (2001). Blushing and physiological arousability in social phobia. Journal of Abnormal Psychology, 110, 247-258.

Goffman, E. (1967). Interaction ritual: Essays on face-to-face behavior. Garden City: Anchor.

Heinrichs, N., \& Hofmann, S. G. (2001). Information processing in social phobia: A critical review. Clinical Psychology Review, 21, 751-770.

Jones, E. E., \& Davis, K. E. (1965). From acts to dispositions: The attribution process in person perception. In L. Berkowitz (Ed.). Advances in experimental social psychology, Vol. 2. New York: Academic Press.

Keltner, D. (1995). Signs of appeasement: Evidence for the distinct displays of embarrassment, amusement, and shame. Journal of Personality and Social Psychology, 68, 441-454.

Keltner, D., Young, R. C., \& Buswell, B. N. (1997). Appeasement in human emotion, social practice, and personality. Aggressive Behavior, 23, 359-374.

Leary, M. (1983). A brief version of the Fear of Negative Evaluation Scale. Personality and Social Psychology Bulletin, 9, 371-375.

Leary, M. R., Britt, T. W., Cutlip II, W. D., \& Templeton, J. L. (1992). Social blushing. Psychological Bulletin, 112, 446-460.

Leary, M. R., Landel, J. L., \& Patton, K. M. (1996). The motivated expression of embarrassment following a self-presentational predicament. Journal of Personality, 64, 619-636.

Leary, M. R., \& Meadows, S. (1991). Predictors, elicitors, and concomitants of social blushing. Journal of Personality and Social Psychology, 60, 254-262.

Mulkens, S., Bögels, S. M., De Jong, P. J., \& Louwers, J. (2001). Fear of blushing: Effects of task concentration training versus exposure in vivo on fear and physiology. Journal of Anxiety Disorders, 15, 413-432.

Mulkens, S., De Jong, P. J., Dobbelaar, A., \& Bögels, S. M. (1999). Fear of blushing: Fearful preoccupation irrespective of facial coloration. Behaviour Research and Therapy, 37, 1119-1128.

Scholing, A., \& Emmelkamp, P. M. (1993). Cognitive and behavioural treatments of fear of blushing, sweating, or trembling. Behaviour Research and Therapy, 31, 155-170.

Semin, G. R., \& Manstead, A. S. R. (1982). The social implications of embarrassment displays and restitution behavior. European Journal of Social Psychology, 12, 367-377.

Shields, S. A., Mallory, M. E., \& Simon, A. (1990). The experience and symptoms of blushing as a function of age and reported frequency of blushing. Journal of Nonverbal Behavior, 14, 171-187.

Stopa, L., \& Clark, D. M. (2000). Social phobia and interpretation of events. Behaviour Research and Therapy, 38, 273-283.

Vorauer, J. D. (2001). The other side of the story: Transparancy estimation in social interaction. In B. Gordon, \& Moskowitz (Eds.). Cognitive social psychology. London: Lawrence Erlbaum.

Vorauer, J. D., \& Miller, D. T. (1997). Failure to recognize the effect of implicit social influence on the presentation of self. Journal of Personality and Social Psychology, 73, 281-295. 